\title{
A new boost dc-dc converter of high efficiency by using a partial resonant circuit
}

\author{
Dong-Kurl Kwak ${ }^{\mathrm{a})}$ \\ Professional Graduate School of Disaster Prevention, University of Kangwon \\ 1 JoongAng-ro, Samcheok-si, Gangwondo, 245-711, Korea \\ a)dkkwak@kangwon.ac.kr
}

\begin{abstract}
This paper presents a new boost dc-dc converter with high efficiency by using a partial resonant circuit. The switching devices in the proposed converter are operated by a soft-switching technique (ZCS; zero current switching, or ZVS; zero voltage switching) of a new partial resonant circuit. The partial resonant circuit makes use of a step-up inductor and a loss-less snubber capacitor. The switching control technique is simplified for the switches to drive in constant switching frequency with PWM (pulse width modulation). The results are that the switching power loss is very low and the system efficiency is high.
\end{abstract}

Keywords: boost dc-dc converter, soft-switching technique, loss-less snubber, partial resonant circuit

Classification: Science and engineering for electronics

\section{References}

[1] E. R. C. Silva, M. C. Cavalcanti, and C. B. Jacobina, "Comparative Study of Pulsed DC-Link Voltage Converters," IEEE Trans. PE, vol. 18, no. 4, pp. 1028-1033, July 2003.

[2] Y. Tsuruta and A. Kawamura, "A High Efficiency and High Power Chopper Circuit QRAS using Soft-Switching under Test Evaluation at $8 \mathrm{KW}$," J. Power Electron., vol. 6, no. 1, pp. 1-7, Jan. 2006.

[3] IEEJ: "Recent development on soft-switching," IEEJ Technical Report, no. 899, pp. 4-8, Sept. 2002 (in Japanese).

[4] X. Ruan, Z. Chen, and W. Chen, "Zero-Voltage-Switching PWM Hybrid Full-Bridge Three-Level-Converter," IEEE Trans. PE, vol. 20, no. 2, pp. 395-404, March 2005.

[5] O. Garcia, J. A. Cobos, et al., "Single-phase power factor correction: A survey," IEEE Trans. PE, vol. 18, no. 3, pp. 749-755, May 2003.

[6] D. Sadarnac, W. Abida, and C. Karimi, "The Double Discontinuous Mode Operation of a Converter: A method for soft-switching," IEEE Trans. PE, vol. 19, no. 2, pp. 453-460, March 2004.

[7] S. K. Chung and J. G. Lim, "Design of Bootstrap Power Supply for HalfBridge Circuits using Snubber Energy Regeneration," J. Power Electron., vol. 7, no. 4, pp. 294-300, Oct. 2007. 


\section{Introduction}

Equipment and machinery which supply dc electricity energy require the boost dc-dc converter of high efficiency by active switching modes to make the most use of the provided energy. The switching frequency of the converter must be increased in order to achieve small size, light weight and low noise [1]. However, the switches in the converter are subjected to high switching losses and stresses. As a result, the converter brings on low efficiency. Recently, to improve the efficiency, a number of soft-switching topologies including resonant circuits have been proposed [2, 3, 4]. However, these converters increase the number of switches and complicate the sequence of switching operation.

This paper describes a new boost dc-dc converter with high efficiency. The switches in the converter are operated by a soft-switching technique of a new partial resonant circuit. The partial resonant operation makes ZCS or ZVS for the control switches without switching losses so called "soft-switching" [3, $4,5]$. The switching control technique of the proposed converter is simplified for the switches to drive in constant switching frequency $[4,6]$.

\section{Configuration and operation principle of proposed converter}

Figures 1 (a) and 1 (b) show a conventional boost converter and a proposed

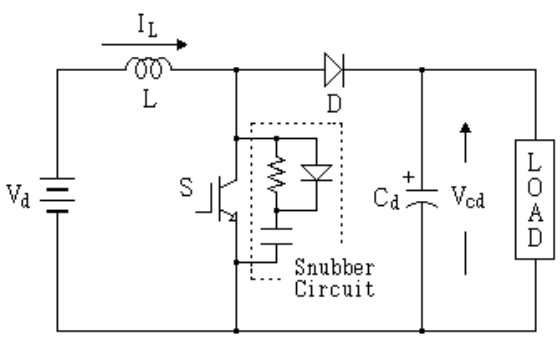

(a)

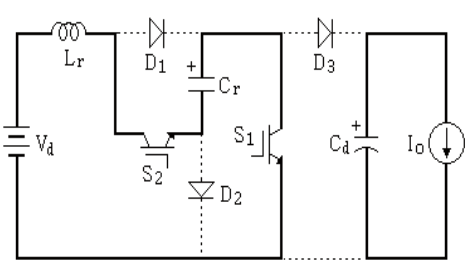

$<$ Mode $1>$

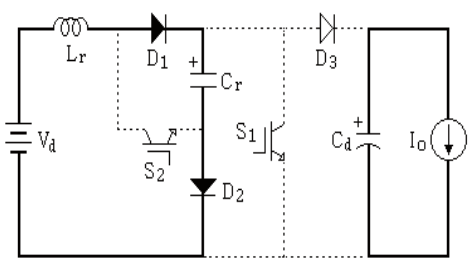

$<$ Mode $3>$

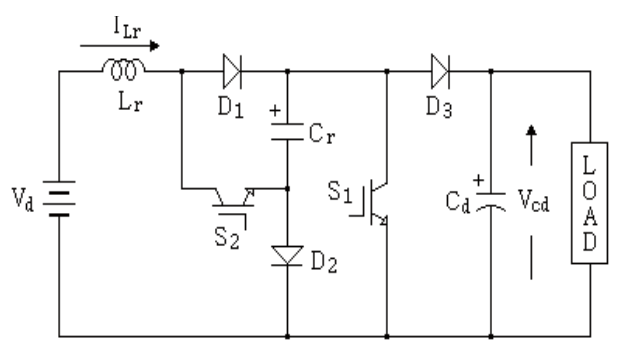

(b)

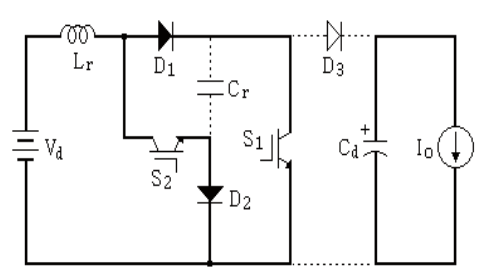

$<$ Mode 2>

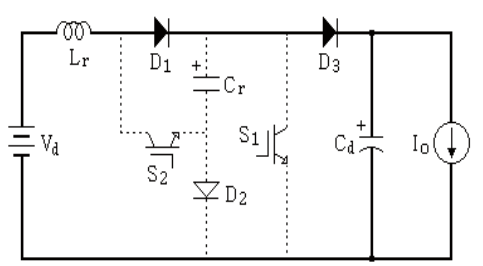

$<$ Mode 4>

(c)

Fig. 1. Configurations of (a) conventional and (b) proposed boost dc-dc converters. (c) Equivalent circuits of operational modes in one cycle switching of the proposed converter. 
new boost converter. The proposed converter is composed of controlling devices, a step-up inductor $L_{r}$, and a snubber capacitor $C_{r}$ used in similar way for the conventional converter. Furthermore, the current flowing through the inductor $L_{r}$ is controlled to be discontinuous [6,7], then the turn-on operation of the switches $S_{1}$ and $S_{2}$ becomes to be ZCS. The turn-off of the switches is also operated with ZVS by the partial resonant operation. Figure 1 (c) shows 4-equivalent circuits for operational modes in one cycle switching. The load side can be considered as a constant current source Io for one cycle switching (about $50 \mu \mathrm{s}$ ), which is caused by an output smoothing capacitor $C d$ of a great capacitance [7].

Mode $1\left(T_{1}: \mathrm{t}_{0} \leq \mathrm{t}<\mathrm{t}_{1}\right)$

Mode 1 begins by turning on both $\mathrm{S}_{1}$ and $\mathrm{S}_{2}$. This mode takes the form of a series $L C$ resonance. The capacitor $C_{r}$ discharges its electric charge through the inductor $L_{r}$. The turn-on switching occurs at zero current. The capacitor voltage is expressed as Eq. (1) and the inductor current increases according to Eq. (2).

$$
\begin{aligned}
& v_{c r}=\left(V_{d}+V_{c d}\right) \cos \omega_{r}\left(t-t_{0}\right)-V_{d} \\
& i_{L r}=\frac{V_{d}+V_{c d}}{X} \sin \omega_{r}\left(t-t_{0}\right)
\end{aligned}
$$

where $\omega_{r}=1 / \sqrt{L_{r} C_{r}}, X=\sqrt{L_{r} / C_{r}}$.

This mode ends when $v_{c r}=0$. The time duration $T_{1}$ of this mode is evaluated as

$$
T_{1}=\sqrt{L_{r} C_{r}} \cos ^{-1}\left(\frac{V_{d}}{V_{d}+V_{c d}}\right)
$$

the inductor current $I_{1}$ at the end of this mode is given by

$$
I_{1}=\frac{1}{X} \sqrt{V_{c d}^{2}+2 V_{d} V_{c d}}
$$

\section{Mode $2\left(T_{2}: \mathrm{t}_{1} \leq \mathrm{t}<\mathrm{t}_{2}\right)$}

Mode 2 begins when $v_{c r}$ becomes zero. Then diodes $\mathrm{D}_{1}$ and $\mathrm{D}_{2}$ start conduction. The inductor current linearly increases according to the following equation:

$$
i_{L r}=\frac{V_{d}}{L_{r}}\left(t-t_{1}\right)+I_{1}
$$

This mode ends when both $\mathrm{S}_{1}$ and $\mathrm{S}_{2}$ are turned off. The time duration $T_{2}$ of this mode can be obtained as the following:

$$
T_{2}=T_{o n}-T_{1}
$$

where $T_{o n}$ is the turn-on time of switches. The inductor current $I_{2}$ at the end of this mode is given by

$$
I_{2}=\frac{V_{d}}{L_{r}} T_{2}+I_{1}
$$

\section{Mode $3\left(T_{3}: \mathrm{t}_{2} \leq \mathrm{t}<\mathrm{t}_{3}\right)$}

Mode 3 begins by turning off both $S_{1}$ and $S_{2}$. The inductor current charges $C_{r}$. This mode also forms a series $L C$ resonance. The turn-off of 
switches occurs at zero voltage because the voltage of $C_{r}$ is zero. In this mode, the capacitor voltage and the inductor current are evaluated as follows:

$$
\begin{aligned}
& v_{c r}=V_{d}+\sqrt{\frac{L_{r}}{C_{r}}} I_{a} \sin \left[\omega_{r}\left(t-t_{2}\right)+\theta\right] \\
& i_{L r}=I_{a} \cos \left[\omega_{r}\left(t-t_{2}\right)+\theta\right]
\end{aligned}
$$

where $I_{a}=\sqrt{\frac{C_{r}}{L_{r}} V_{d}^{2}+I_{2}^{2}}, \theta=\sin ^{-1}\left(-\frac{V_{d}}{\sqrt{V_{d}^{2}+\frac{L_{r}}{C_{r}} I_{2}^{2}}}\right)$.

When $v_{c r}$ becomes equal to $V_{c d}$ and $\mathrm{D}_{3}$ starts conduction, this mode ends. The time duration $T_{3}$ of this mode is expressed as

$$
T_{3}=\sqrt{L_{r} C_{r}}\left[\sin ^{-1}\left(\frac{V_{c d}-V_{d}}{\sqrt{V_{d}^{2}+\frac{L_{r}}{C_{r}} I_{2}^{2}}}\right)-\theta\right]
$$

and the inductor current $I_{3}$ at the end of this mode is given by

$$
I_{3}=I_{2} \cos \omega_{r} T_{3}+\sqrt{\frac{C_{r}}{L_{r}}} V_{d} \sin \omega_{r} T_{3}
$$

$\underline{\text { Mode } 4}\left(T_{4}: \mathrm{t}_{3} \leq \mathrm{t}<\mathrm{t}_{4}\right)$

In this mode, the inductor current flows into the load. The current linearly decreases as

$$
i_{L r}=\frac{V_{d}-V_{c d}}{L_{r}}\left(t-t_{3}\right)+I_{3}
$$

This mode ends when $i_{L r}=0$. Time duration $T_{4}$ is expressed as

$$
T_{4}=\frac{L_{r}}{V_{c d}-V_{d}} I_{3}
$$

\section{Computer simulation and experimental results}

The proposed converter was analyzed by Pspice program. The output voltage was regulated at dc $300 \mathrm{~V}$ with dc $100 \mathrm{~V}$ input. $L_{r}$ and $C_{r}$ were selected at $70 \mu \mathrm{H}$ and $100 \mathrm{nF}$, respectively. The capacitor $C_{d}$ was $2000 \mu \mathrm{F}$, and the output load was replaced by a constant current source of $3 \mathrm{~A}$. Switching frequency was $20 \mathrm{kHz}$ and duty cycle was regulated at $30 \%$.

Figures $2(\mathrm{a})$ and $2(\mathrm{~b})$ show the waveforms of each part in one cycle switching. $V_{g 1}$ and $V_{g 2}$ are the gate signals of switches $\mathrm{S}_{1}$ and $\mathrm{S}_{2}, v_{s 1}$ and $v_{s 2}$ are voltages across the switches, $i_{s 1}$ and $i_{s 2}$ are currents flowing through the switches.

The switches are turned on at $\mathrm{t}_{0}$ and $C_{r}$ begins to discharge. $v_{c r}$ becomes zero at $\mathrm{t}_{1}$. At $\mathrm{t}_{2}$, the switches are turned off, $C_{r}$ is charged by $i_{L r}$, and $v_{c r}$ becomes $V_{c d}$ at $\mathrm{t}_{3}$. At $\mathrm{t}_{4}, i_{L r}$ reaches zero and the switches are kept off till the next cycle. As the current of switches is zero at $t_{0}$, the switches are turned on at ZCS condition. As the voltage across switches is also zero at $t_{2}$, the switches are turned off at ZVS condition.

At Figures 2 (c) and $2(\mathrm{~d})$, the switch V-I locus for the conventional converter has a large area, but for the proposed soft-switching converter, it has only a small area. The area surrounded is proportional to the switching loss. 


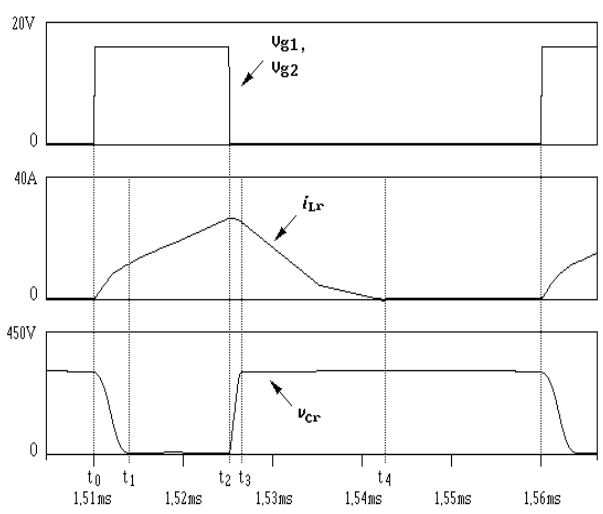

(a)

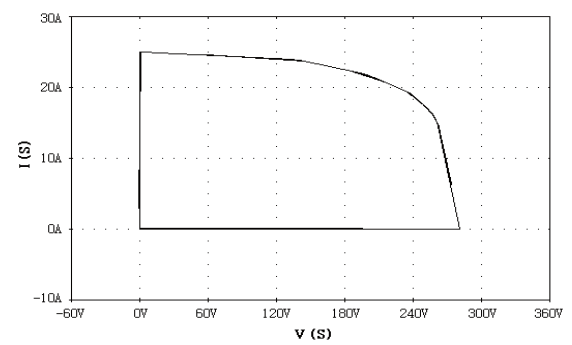

(c)

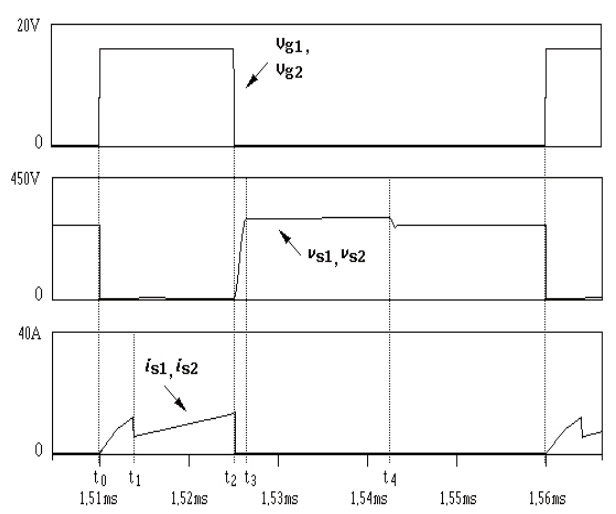

(b)

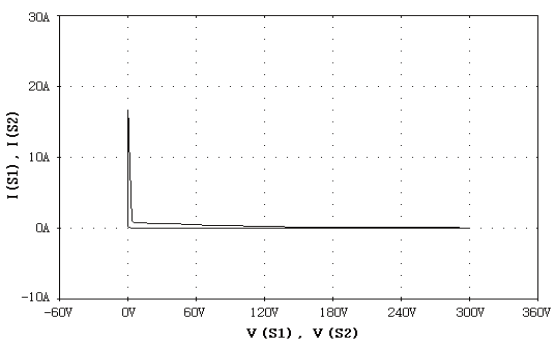

(d)

Fig. 2. Simulation waveforms in one cycle switching: (a) inductor current and capacitor voltage and (b) voltage and current of switches for the proposed dc-dc converter. V-I loci of the controlling switches for (c) the conventional converter and (d) the proposed converter.

In order to confirm the feasibility, the proposed converter was experimented to output a rated power of $1.0 \mathrm{~kW}$. The input voltage source was supplied from the batteries of dc $100 \mathrm{~V}(25 \mathrm{~V} \times 4$ units $)$, and the output voltage is fixed at dc $300 \mathrm{~V}$. The output load was composed of a variable wiring resistor with the range of $10 \Omega$ to $1000 \Omega$ of $1.0 \mathrm{~kW}$. Figures 3 (a) and 3 (b) show the waveforms of each part with a duty cycle of $30 \%$, switching frequency of $20 \mathrm{kHz}$. The switches were operated with the soft-switching, namely turn-on at zero current and turn-off at zero voltage according to partial resonant operation. The power losses of main devices are shown in Figure 3 (c), respectively. Figure 3 (d) shows the relationship between system efficiency and output power. The output power was measured in the adjusted range of the variable resistor with PWM switching control. The snubber circuit in the conventional converter [Fig. 1 (a)] was also composed of a snubber resistor of $50 \Omega$ and a snubber capacitor of $0.47 \mu \mathrm{F}$, which was generally used in hard-switching converters. Figure 3 (e) shows the relationship between output voltage and duty cycle with the load resistor $1000 \Omega$. As the charged voltage of capacitor $C_{r}$ was added to input power source, the proposed converter generated higher output voltage than the conventional converter. To achieve discontinuous current mode (DCM), the duty cycles of the proposed converter and the conventional converter were measured and regulated below 


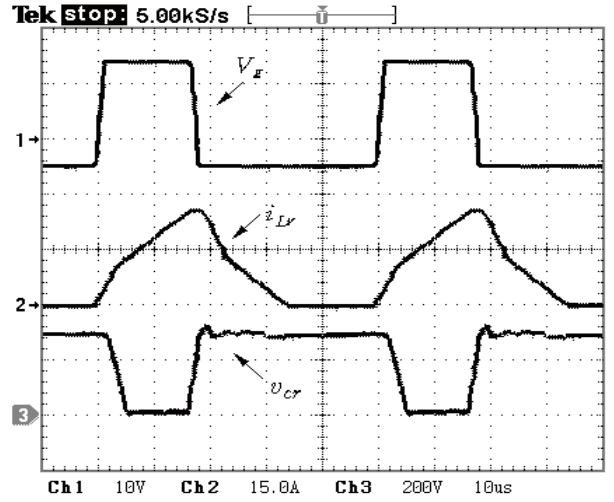

(a)

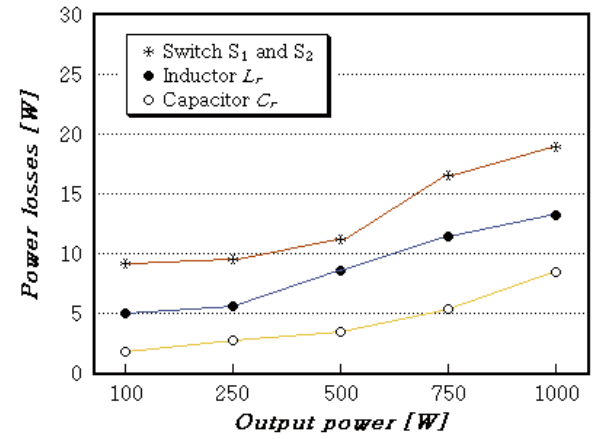

(c)

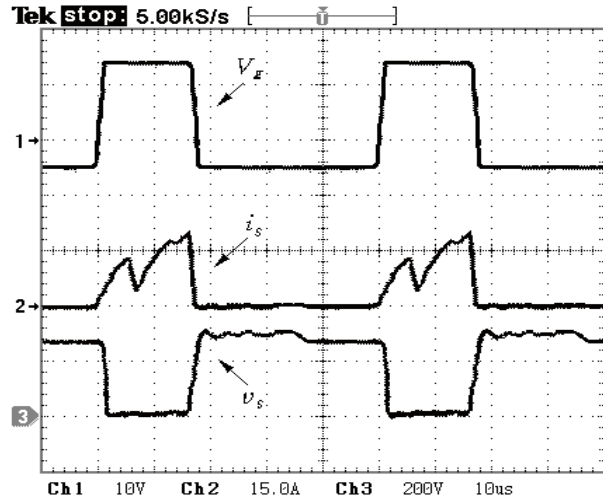

(b)

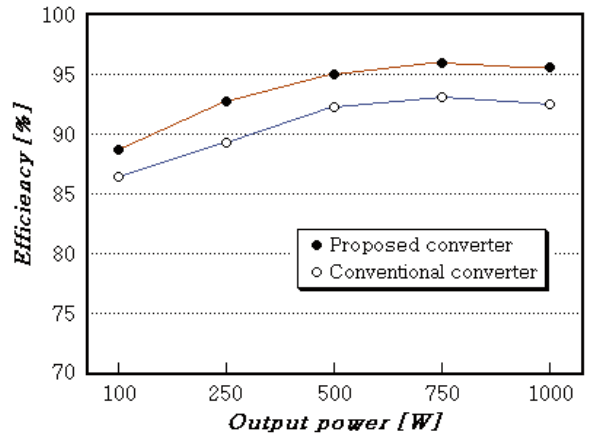

(d)

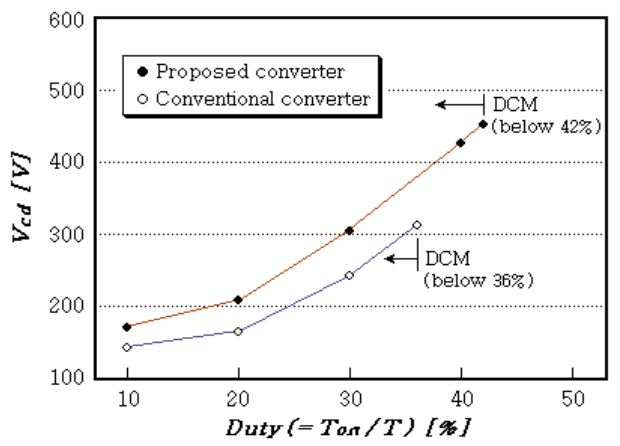

(e)

Fig. 3. Experimental waveforms in one cycle switching: (a) inductor current and capacitor voltage, (b) voltage and current of switch. (c) Power losses of main devices, (d) Measured efficiency comparison, and (e) Measured output voltage comparison with DCM.

$42 \%$ and $36 \%$, respectively, under the experimental condition.

\section{Conclusion}

A new boost dc-dc converter with high efficiency has been presented in this paper. To achieve the soft-switching of the controlling switches, the proposed boost converter applied a partial resonant circuit using a step-up inductor and a loss-less snubber capacitor. The accumulated energy in the loss-less snubber capacitor was regenerated into the input power source by the partial resonant 
operation. The switching control technique of the proposed converter was simplified for the switches to drive in a constant switching frequency with PWM. The results were that the switching power losses were very low and the system efficiency was high. 